УДК 94(47).084.5/.6+39(470.344)“"192/193”

DOI 10.18413/2687-0967-2020-47-2-350-358

\title{
ТРАНСФОРМАЦИЯ ПЕСЕННОГО ФОЛЬКЛОРА ЧУВАШЕЙ В 20-30-е ГОДЫ ХХ ВЕКА: К ВОПРОСУ О «СОВЕТИЗАЦИИ» ТРАДИЦИОННОЙ КУЛЬТУРЫ
}

\section{TRANSFORMATION OF SONG FOLKLOR OF THE CHUVASHI IN THE 20-30s OF THE XX CENTURY: ON THE ISSUE OF THE «SOVIETIZATION» OF TRADITIONAL CULTURE}

\author{
В.В. Медведев, М.В. Попов \\ V.V. Medvedev, M.V. Popov \\ Сургутский государственный педагогический университет, \\ Россия, 628400, г. Сургут, ул. 50 лет ВЛКСМ, д. 10/2 \\ Магнитогорский государственный технический университет им. Г.И. Носова, \\ Россия, 455000, г. Магнитогорск, пр. Ленина, д. 38
}

Surgut State Pedagogical University, Russia, 10/2 50 let VLKSM St, Surgut, 628400, Russia

Nosov Magnitogorsk State Technical University, Russia, 38 Lenin Av, Magnitogorsk, 455000, Russia

E-mail: vlad.etno@mail.ru, maxim_popov@hotmail.com

\begin{abstract}
Аннотация
Новизна исследования заключается в том, что в работе продемонстрирован вариант интеграции чувашей в формирующуюся советскую культуру через трансформацию традиционного песенного творчества. «Советизация» чувашей, как и других народов, предполагалась как «ассимиляция советским обществом», с привлечением пропаганды и распространением образцов советской культуры. «Советизация» песенного фольклора чувашей негативно повлияла на аутентичную музыку. В 1930-х годах тексты народных песен, не переработанные в соответствии с новыми ориентирами, были признаны неактуальными и исчезли из репертуара профессиональных исполнителей. В условиях трансформации традиционной культуры «советизация» песенного фольклора чувашей представляла собой обоснованный и востребованный для своего времени процесс. Включение новых культурных форм и повседневных практик в традицию народа создало иной тип культуры - советский, элементы которого и сегодня наблюдаются в современной культуре чувашей.
\end{abstract}

\begin{abstract}
The sphere of political interests of the new Soviet leadership covered all aspects of traditional folk culture. Particular attention was given to cultural practices as an important element in the field of politics and ideology in the system of new social relations. The construction of new cultural images met the requirements of the young Soviet state and served as the basis for the interpretation of events and the emerging self-awareness of people. The concept of «Sovietization» involves the use of a number of cultural practices. An example is the practice with the indigenous peoples of the North, whose «Sovietization» was thought of as «assimilation» by the Soviet society, with the involvement of propaganda and the dissemination of samples of Soviet culture. Similar processes of «Sovietization» of traditional culture, language and literature took place among the Chuvashs. These processes contributed to the subsequent integration of the Chuvash into the emerging Soviet culture. The «Sovietization» of the traditional Chuvash culture influenced everyday life and mentality, was introduced into the tradition and changed it. The transformation is clearly observed in anthroponyms and oikonyms, ritual practices, folklore and other areas of material and spiritual culture. From the first years of the establishment of Soviet power, folklore was influenced by «Sovietization». The transformation of songwriting manifested itself in various aspects. The «Sovietization» of the Chuvash folklore negatively affected authentic music. In the 1930s, lyrics of folk songs that were not revised in accordance with the new guidelines were deemed irrelevant and disappeared from the repertoire of professional performers. In the context of the
\end{abstract}


transformation of traditional culture, the «Sovietization» of the Chuvash song folklore was a justified and demanded process for its time. The inclusion of new cultural forms and everyday practices in the tradition of the people created a different type of culture - Soviet, whose elements are observed today in the modern Chuvash culture.

Ключевые слова: «советизация», чуваши, традиционная культура, трансформации, песенный фольклор.

Keywords: «sovietization», Chuvashes, traditional culture, transformations, song folklore.

Проблемы формирования единой советской культуры, предназначенной объединить население и представителей всех этнических групп новой Советской России, всегда актуальны и являются предметом исследований историков, антропологов и культурологов. В своих работах исследователи прежде всего обращают внимание на культурные практики и процессы трансформации традиционной культуры в условиях «советизации». Среди подобных изданий следует выделить публикации П.Е. Азаровой [2011], С.Д. Багдасарян [2013], Ф.Г. Галиевой [2017; 2018], Е.В. Поповой [2017] и ряда других авторов. Фундаментальным трудом, рассматривающим особенности ранней истории Советской России в контексте культурного дискурса, трансформации повседневных практик, образа мышления, мировоззрения и «народной культуры по поручению правительства» является исследование Ш. Плаггенборга «Революция и культура: культурные ориентиры в период между Октябрьской революцией и эпохой сталинизма» [Плаггенборг, 2000].

Становление новых культурных практик и нового сознания происходило в соответствии с первыми декретами СНК. Таковыми, например, стали Декреты «О свободе совести, церковных и религиозных обществах» от 20 января 1918 г. [Декреты, 1957, c. 373-374], «О введении в Российской республике западноевропейского календаря» от 24 января 1918 г. [Декреты, 1959, с. 95-97], «О снятии памятников, воздвигнутых в честь царей и их слуг, и выработке проектов памятников Российской Социалистической Революции» от 12 апреля 1918 г. [Декреты, 1957, с. 404-405] и т. д. Декреты и сопутствующие им документы послужили фундаментом для осуществления «советизации» территорий и населения Советской России.

Содержание понятия «советизация» подразумевает не только поэтапное учреждение советской власти, национализацию земель и изменения на государственном и социально-экономическом уровне, но и внедрение единых образцов советского образа жизни. Следует подчеркнуть, что конструирование новых культурных практик и образов не только соответствовало требованиям советской власти, но и служило основой интерпретации происходивших событий и формирующегося самосознания людей [Шнирельман, 2016; Макарова, 2017].

Наряду с понятием «советизация» в науке также используется термин «советскость». Примером этого служит монография антрополога С.Н. Абашина «Советский кишлак: между колониализмом и модернизацией», рассматривающей преобразования на территории Средней Азии с конца XIX века и до распада Советского Союза [Абашин, 2015].

«Советизация» традиционной культуры чувашей, как и традиционной культуры других народов, влияла на повседневность и ментальность, внедрялась в традицию и изменяла её. Такая трансформация отчётливо наблюдается в измененных антропонимах и ойконимах, ритуальных практиках, а также в других областях материальной и духовной культуры чувашей [Медведев, Малахова, 2018].

Аналогичные процессы происходили и с формирующейся национальной чувашской литературой [Кирчанов, 2013]. В подобном положении находились все народы Советской России, поскольку вопросы культурного строительства регламентировали и унифицировали постановления партии. Например, содержание литературных произведений 
отвечало требованиям постановления «О политике партии в области художественной литературы», в котором ставился акцент «на развитие национальной литературы в многочисленных республиках и областях нашего Союза» [Постановление, 1925]. Подобные документы определяли и упорядочивали творческую деятельность советской интеллигенции [Постановление, 1932].

Реалии нового советского времени отразились в устном творчестве чувашей. С первых лет становления новой власти фольклор был подвержен «советизации». На чувашском языке стали исполняться песни «Варшавянка», «Дубинушка», «Смело, товарищи, в ногу!», «Интернационал», «Крестьянская марсельеза», быстро ставшие популярными среди молодёжи. Например, по воспоминаниям Е.В. Сантиметровой (1921 г. р.), одной из песен, услышанных в раннем детстве и достаточно часто исполняемой на чувашском языке односельчанами на праздниках и в будние дни, был «Интернационал» [Медведев, 2009]. А.И. Прокопьев (1926 г. р.) упоминал, что в 30-х гг. прошлого столетия одной из наиболее распространённых песен, исполняемых в его родном селе, была «Песня о Щорсе», также исполняемая на чувашском языке [Медведев, 2018]. Песенное литературное творчество этого времени, сами песни «являются утверждением новой, социалистической действительности и нового человека $<\ldots>$ коренные изменения во всём укладе жизни сказались и на идейном содержании, и жанровых формах народного творчества» [Чуваши, 1970, c. 212-213].

Трансформация песенного творчества проявилась в разных аспектах. Мелодии и переведённые тексты, нередко имеющие слова литературного происхождения, составили новую музыкальную основу. Стили инструментальных наигрышей отчасти совпадали со стилем традиционных песен [Чуваши, 2017, с. 529-530]. Тексты были дополнены отдельными предложениями или самостоятельными куплетами, посвященными новой жизни и советским преобразованиям. Но переводческая деятельность, развернувшаяся в отношении песенных текстов, не смогла полноценно разрешить проблему их восприятия, поскольку песенный интонационный строй был непонятен и непривычен чувашам [Погодина, 2011].

Особую популярность среди населения имели такмаки - «частушки». Так у народных исполнителей нередко именуются все краткие песни, вне зависимости от их содержания и назначения [Исмагилова, 2017]. Такмаки подразделяют на плясовые, свадебные, сатирические и игровые. В советское время среди чувашей распространяются такмаки об организации колхозов, комсомоле, новом быте, Советской Армии, ударниках социалистического труда. Приведём примеры такмаков, переведенных с чувашского языка: «Складчатая-складчатая гармошка, одна складка излишняя. Когда строится новая жизнь, поп и кулак излишни», «Подсолнухи, цветущие в огороде, подобны сорока и одному солнышку. Люди нашей страны подобны родным одной семьи», «Макушку ржаной скирды треплет ветер, Красная Армия гонит прочь Деникина. Крапива, что растёт на краю глубокого оврага, пригибается от ветра, Красная Армия громит Деникина и Колчака» [Чуваши, 1970, c. 214].

Наряду с данными произведениями появляются такмаки с выраженным антирелигиозным контекстом, что формирует самостоятельную группу фольклорного материала. Например, «Если нынче лён родится, готовь прялку, если в церковь я пойду, плюнь мне в глаза», «Ах ты, яблочко, катись, ведь дорога скользкая. Подкузьмила всех святых, Пасха комсомольская», «Какой ширины рукава у попа? Ха-ха-ха! Наверное, полтора аршина будут, хи-хи-хи! Волосы у дьякона полтора метра, ха-ха-ха!» [Козлов]. Антирелигиозный контекст стал характерной чертой многих пословиц и поговорок.

Музыкально и поэтически обработанные чувашские народные песни, отражающие советскую действительность, были собраны и опубликованы в сборниках: «Революци юррисем» («Песни Революции»), «Сыхлӑх юрри» («Песня обороны»), «С̧ӗнӗ юрӑсем» («Новые песни»), «Колхозниксен есс юрри» («Колхозная трудовая»), «Сӑрнай» («Зурна»), «С̧ӗнӗ сӑрнай» («Новая зурна»), «Шкул юррисем» («Школьные песни»), «Чӑваш халӑхӗн 
13 çӗнӗ пурнӑс̧ юрри» («13 чувашских песен нового быта») и другие. Советский композитор Ф.П. Павлов, фиксировавший песенный фольклор чувашей, анализируя собранный в одном из своих рукописных сборников материал, подготовленный к печати, делает заметку: «Составитель имеет в виду пополнить некоторые отделы его новыми песнями и мотивами, появившимися за время революции, в которых ярко отразился новый быт» [Павлов, 1926, с. 46]. К моменту записи в разделе сборника «Революционные песни» находилась всего одна композиция.

Советские идеологические установки формируют песенный репертуар первых профессиональных чувашских композиторов, отражающий реалии своего времени. Например, произведение В.П. Воробьева «Ленин» создаёт представление об образе В.И. Ленина, а «Пионерская песня» С.М. Максимова транслирует лозунги пионерского движения [Погодина, 2011].

Одновременно с этим композитор С.М. Максимов, будучи одним из первых представителей профессиональной школы, считал, что «строительство социалистической культуры в национальных условиях требует создания национальной музыки с её характерными особенностями» [Максимов, 1929, с. 71]. Он полагал, что это возможно только с учетом опыта традиционной музыкальной культуры и наследия устного творчества чувашского народа. С.М. Максимов отмечал приверженность традиционным культурным ориентирам песенного творчества и фольклора в целом, понимая, что изменения в хозяйственном укладе, социальные преобразования и «идеологические сдвиги получают отражение не тотчас, а с некоторым запозданием» [Максимов, 1934, с. 10].

Известный филолог-фольклорист М.Я. Сироткин в одной из своих работ упоминает показательный случай соединения народного и авторского профессионального творчества. Поэт Н.И. Шелеби сочинил в 1924 г. стихотворение «Ленин», положенное в основу одноимённой песни. Эта песня через 16 лет была зафиксирована уже как народная чувашская песня со слов сельчан колхоза Канаш (Похвистневский район, Куйбышевская область). Стиль и норма исполнения песни демонстрируют её соответствие традиции [Сироткин, 1965, с. 128-129]. В композиции присутствует синтез новой складывающейся советской культуры и традиций народного творчества чувашей, отражён процесс «советизации», одновременно происходивший и в других сферах жизни народа. Появление фольклорных произведений, прославляющих и воспевающих образ В.И. Ленина, т. е. принадлежащих к циклу «народнопоэтической Ленинианы», филологи и фольклористы рассматривают в качестве первого этапа становления «советского фольклора» [Панченко].

«Новое» песенное творчество демонстрируют труды композитора и фольклориста В.П. Воробьева, занимающегося сочинением и обработкой чувашских фольклорных мелодий и текстов. В 1920-1940 гг. им были собраны и записаны многочисленные произведения песенного фольклора. Материалы исследователя в 2011 г. опубликованы самостоятельным изданием «Чувашские народные песни» [Воробьев, 2011].

Книга объединила 196 песен, плачей, такмаков, пеитов и наигрышей. Представленный материал демонстрирует, что процессы «советизации» нашли своё отражение в рекрутских песнях, известных как салтак юррисем (№№ 60, 62) и гостевых/пирушечных песнях - хӑна/е̌ске̌ юррисем (№№ 85, 88, 93, 94, 96, 106, 109 и другие). Содержание текстов посвящено службе в Красной Армии, строительству колхозов и коллективной форме ведения хозяйства, жизни по новым советским нормам и законам. В песнях упоминаются и персоналии: В.И. Ленин, И.В. Сталин, К.Е. Ворошилов. Новая жизнь имеет только положительные черты, о чём, например, говорится в песне «Шупашкар варринче» («В центре Чебоксар») [Воробьев, 2011, с. 104]:

... Дом Советов, большой дом, в большом доме добрые люди, все добрые люди собрались, все добрые песни поют. 
Процесс «советизации» музыкального искусства потребовал от профессионального сообщества композиторов новых произведений и отказа от традиционных этнографических композиций, не отвечавших стандартам и практикам повседневности социалистического общества [Абрукова, 2006, с. 190]. Именно поэтому «советизация» песенного фольклора чувашей негативно сказалась на аутентичной музыке. В 1930-х годах тексты народных песен, не переработанные в соответствии с новыми ориентирами, признаются неактуальными, поскольку не отвечают предъявляемым требованиям и исчезают из репертуара профессиональных исполнителей [Чуваши, 2017, с. 531].

Процесс «советизации» устного творчества чувашей, помимо песенного фольклора, отражается и в иных формах - на примере пословиц, поговорок и загадок. Так, Н.Р. Романов в 1960 г. публикует сборник «Чувашские пословицы, поговорки и загадки». В издании были объединены более 2500 пословиц и поговорок, а также 1700 загадок. Эти произведения чувашского устного народного творчества автор собирал на протяжении 35 лет исследовательской деятельности. В числе тематических разделов - «прошлые времена» (по направлениям народ, хозяйство, труд, человек, семья и другие), а также «новое время», включающий такие поговорки как «Идеи Ленина дороже всего на свете», «Сила колхоза в коллективе», «Колхозное добро - достояние народа», «Каков бригадир, такова и работа» и многие другие [Романов, 1960, с. 180-181].

Морис Хальбвакс о свойствах памяти писал, что «люди порой изменяют свои индивидуальные воспоминания, чтобы согласовать их со своими нынешними мыслями» [Хальбвакс, 2007, с. 283]. Это утверждение вполне справедливо можно применить по отношению к преобразованиям и трансформациям, сопровождавшим песенную традицию чувашей, как и всех других народов в период «советизации» культуры. Песенный фольклор должен был пройти согласование с новыми реалиями и отвечать вызовам времени.

«Советизацию» устного народного творчества чувашей достаточно ярко резюмирует цитата из работы «Поёт чувашский народ»: «Теперь в чувашском крае <...> восторжествовало передовое коммунистическое сознание; вместо тоскливой заунывной песни, оплакивавшей судьбину чувашского крестьянина, зазвучала бодрая жизнеутверждающая песня, песня свободного труда и героической борьбы» [Чуваши, 2017, с. 531-532].

Таким образом, имеющиеся материалы позволили проанализировать трансформацию культурных практик чувашей в 20-30-е гг. XX века и рассмотреть «советизацию» в контексте преобразования песенной традиции и формирования советской культуры. В народной среде изменения традиционных культурных форм не вызывали конфликтной ситуации. Песенный фольклор как в контексте традиционной культуры, так и в период «советизации», позволил выразить самосознание и настроение народа и служил идентифицирующим фактором. Общие процессы, происходящие на территории страны, конкретизировались чувашами посредством песенного фольклора относительно их повседневности. Новые формы и практики, прежде всего, получили распространение среди молодежи, становились модной тенденцией и формой социализации. Через песни, частушки и другие жанры устного творчества переосмыслялся опыт прошлого и ценностные ориентиры. Из контекста содержания песен и такмаков, распространённых в сельских поселениях и городах, можно сделать вывод о положительном восприятии нового образа жизни большинством чувашей.

В условиях трансформации традиционной культуры «советизация» песенного фольклора чувашей представляла собой обоснованный и востребованный для своего времени процесс. Включение новых культурных форм и повседневных практик в традицию народа создало иной тип культуры - советский, элементы которого мы отчасти наблюдаем и сегодня в современной культуре чувашей. 


\section{Список литературы}

1. Абашин С.Н. 2015. Советский кишлак: между колониализмом и модернизацией. М., Новое литературное обозрение, 719.

2. Абрукова Т.А. 2006. Песенное творчество первых чувашских композиторов: к проблеме становления профессионализма. Вестник Чувашского университета. 5: 187-191.

3. Азарова П.Е. 2011. Феномен антипраздника в советской массой культуре $1920-\mathrm{x}-$ середины 1930-х годов. Вестник НГУ. Серия: История, филология. Том 10, выпуск 10: История: 120 124.

4. Багдасарян С.Д. 2013. Советский праздник в российской деревне 1920-х гг. Почему советизация праздничной крестьянской культуры в эпоху нэпа проходила замедленно? Преподавание истории в школе. 3: 76-79.

5. Воробьев В.П. 2011. Чувашские народные песни. Чебоксары, Чувашский государственный институт гуманитарных наук, 328.

6. Галиева Ф.Г. 2017. Антирелигиозные праздники в Башкирии в 1923 г. Вопросы истории. 6: $146-153$.

7. Галиева Ф.Г. 2018. Комсомольский праздник Семык у марийцев Башкирии. Вестник Марийского государственного университета. Серия: Исторические науки. Юридические науки. T. 4. 1.: 15-19.

8. Декреты Советской власти в 5 т. Т. 1. М., Государственное издательство политической литературы, 1957. 626.

9. Декреты Советской власти в 5 т. Т. 2. М., Государственное издательство политической литературы, 1959. 698.

10. Исмагилова Е.И. 2017. Современное состояние песенного фольклора чувашей Сибири. Сибирский филологический журнал. 2: 16-27.

11. Кирчанов М.В. 2013. Унификация текста в чувашской АССР в 1930-е гг. (советизация чувашской литературы). Общественные науки. 2: 28-33.

12. Козлов Ф.Н. Антирелигиозные мотивы в чувашском и марийском советском фольклоpe. URL: http://mognovse.ru/b-antireligioznie-motivi-v-chuvashskom-i-marijskom-sovetskom.html (дата обращения 10 января 2020).

13. Макарова Н.Н. 2017. Религиозная жизнь в Магнитогорске (1930-1980-е гг.). Проблемы истории, филологии, культуры. 2 (56): 146-158.

14. Максимов С.М. 1929. Чувашская музыка. В кн.: Первый всечувашский краеведческий съезд (15-21 июня 1928 года в г. Чебоксарах ЧАССР). Тезисы докладов и резолюции. Чебоксары, Издание общества изучения Чувашского края: 71-79.

15. Максимов С.М. 1934. Вступительная статья. В кн.: 146 песен, записанных от Гаврила Федорова С. Максимовым, Ф. Павловым, В. Воробьевым и Т. Парамоновым. Чебоксары - Москва, Чувашгосиздат-Музгиз: 3-16.

16. Медведев В.В. 2009. Полевой материал автора (Республика Башкортостан, Зилаирский р-н, с. Бердяш).

17. Медведев В.В. 2018. Полевой материал автора (Республика Башкортостан, Кармаскалинский р-н, с. Суук-Чишма).

18. Медведев В.В., Малахова Л.П. 2018. «Советизация» традиционной культуры чувашей в 20-30-е годы ХХ века. Научный диалог. 3: 186-197.

19. Павлов Ф.П. 1926. Чуваши и их песенное и музыкальное творчество. Музыкальноэтнографические очерки. Чебоксары, Общество изучения местного края, 65.

20. Панченко А.A. Культ Ленина и «советский фольклор». URL: http://folk.spbu.ru/Reader/panch2.php?rubr=Reader-articles (дата обращения 10 января 2020).

21. Плаггенборг Ш. 2000. Революция и культура: Культурные ориентиры в период между Октябрьской революцией и эпохой сталинизма. Пер. с нем. И. Карташева. СПб., Нева, 416.

22. Погодина И.П. 2011. Песенное творчество первых чувашских композиторов: идеология и искусство. URL: https://pogodinkk.ucoz.ru/publ/pesennoe_tvorchestvo_pervykh_chuvashskikh_kompozitorov_ideologija_ i_iskusstvo_issledovanie/1-1-0-48 (дата обращения 10 января 2020).

23. Попова Е.В. 2017. Новая (советская) символика и предметный мир крестьянской повседневности. В сб.: Этнокультурные процессы в многонациональном государстве (к 100 -летию ре- 
волюции 1917 года в России). Материалы Шестнадцатых Международных Санкт-Петербургских этнографических чтений. СПб, Российский этнографический музей: 43-47.

24. Постановление Политбюро ЦК РКП(б) «О политике партии в области художественной литературы», 18 июня 1925 г. URL: http://hist.msu.ru/ER/Etext/USSR/1925.htm (дата обращения 10 января 2020).

25. Постановление Политбюро ЦК ВКП(б) «О перестройке литературно-художественных организаций», 23 апреля 1932 г. URL: http://www.refsru.com/referat-16420-16.html (дата обращения 10 января 2020).

26. Романов Н.Р. 1960. Чувашские пословицы, поговорки и загадки. Чебоксары, Чувашское государственное издательство, 359.

27. Сироткин М.Я. 1965. Чувашский фольклор: очерк устно-поэтического народного творчества. Чебоксары, Чувашское книжное издательство, 132.

28. Хальбвакс М. 2007. Социальные рамки памяти. Пер. с фр. и вступительная статья С.Н. Зенкина. М., Новое издательство, 348. (Halbwachs M. 1994. Les cadres sociaux de la mémoire. Paris, Albin Michel, 374).

29. Чуваши. М., Наука, 2017.

30. Чуваши: этнографическое исследование. Ч. 2. Духовная культура / Под редакцией М.Я. Сироткина, М.И. Иванова, Чебоксары, Чувашское книжное издательство, 1970. 308.

31. Шнирельман В.А. 2016. Социальная память и образы прошлого. Новое прошлое. 1: $100-123$

\section{References}

1. Abashin S.N. 2015. Sovetskiy kishlak: mezhdu kolonializmom i modernizatsiey [Soviet kishlak: between colonialism and modernization]. Moscow, Novoe literaturnoe obozrenie, 719 (in Russian).

2. Abrukova T.A. 2006. Pesennoe tvorchestvo pervykh chuvashskikh kompozitorov: k probleme stanovleniya professionalizma [Songwriting of the first Chuvash composers: to the problem of the formation of professionalism]. Vestnik Chuvashskogo universiteta [Bulletin of the Chuvash University]. 5: 187-191 (in Russian).

3. Azarova P.E. 2011. Fenomen antiprazdnika v sovetskoy massoy kul'ture 1920-kh - serediny 1930-kh godov [The phenomenon of opposite holiday in the Soviet mass culture of the 1920s - mid1930s]. Vestnik NGU. Seriya: Istoriya, filologiya [Vestnik NSU. Series: History and Philology]. Tom 10, vypusk 10: Istoriya: 120-124 (in Russian).

4. Bagdasaryan S.D. 2013. Sovetskiy prazdnik v rossiyskoy derevne 1920-kh gg. Pochemu sovetizatsiya prazdnichnoy krest'yanskoy kul'tury v epokhu nepa prokhodila zamedlenno. Prepodavanie istorii v shkole [Soviet holiday in the Russian village of the 1920-s. Why Sovietization festive peasant culture in the era of the NEP passed slowly. The teaching of history in schools]. 3: 76-79 (in Russian).

5. Vorob'ev V.P. 2011. Chuvashskie narodnye pesni [Chuvash folk songs]. Cheboksary, Chuvashskiy gosudarstvennyy institut gumanitarnykh nauk, 328 (in Russian).

6. Galieva F.G. 2017. Antireligioznye prazdniki v Bashkirii v 1923 g. Voprosy istorii [Antireligious holidays in Bashkiria in 1923. Issues of history]. 6: 146-153 (in Russian).

7. Galieva F.G. 2018. Komsomol'skiy prazdnik Semyk u mariytsev Bashkirii. Vestnik Mariyskogo gosudarstvennogo universiteta. Seriya: Istoricheskie nauki. Yuridicheskie nauki [Komsomol festival Semyk with the Mari of Bashkiria. Vestnik of the Mari State University. Chapter: History. Law]. T. 4. 1: 15-19 (in Russian).

8. Dekrety Sovetskoy vlasti v 5 t. [Decrees of the Soviet government in 5 v.]. T. 1. Moscow, Gosudarstvennoe izdatel'stvo politicheskoy literatury, 1957. 626 (in Russian).

9. Dekrety Sovetskoy vlasti v 5 t. [Decrees of the Soviet government in 5 v.]. T. 2. Moscow, Gosudarstvennoe izdatel'stvo politicheskoy literatury, 1959. 698 (in Russian).

10. Ismagilova E.I. 2017. Sovremennoe sostoyanie pesennogo fol'klora chuvashey Sibiri. Sibirskiy filologicheskiy zhurnal [The present state of the song folklore of the Chuvashes of Siberia. Siberian Journal of Philology]. 2: 16-27 (in Russian).

11. Kirchanov M.V. 2013. Unifikatsiya teksta v chuvashskoy ASSR v 1930-e gg. (sovetizatsiya chuvashskoy literatury) Obshchestvennye nauki [Unification of the text in the Chuvash Autonomous Soviet Socialist Republic in the 1930s. (Sovietization of Chuvash literature) Social Science]. 2: 28-33 (in Russian). 
12. Kozlov F.N. Antireligioznye motivy v chuvashskom i mariyskom sovetskom fol'klore [Antireligious motives in the Chuvash and Mari Soviet folklore]. Available at: http://mognovse.ru/bantireligioznie-motivi-v-chuvashskom-i-marijskom-sovetskom.html (accessed 10 January 2020) (in Russian).

13. Makarova N.N. 2017. Religioznaya zhizn' v Magnitogorske (1930-1980-e gg.). Problemy istorii, filologii, kul'tury [Religious life in Magnitogorsk in 1930-1980. Journal of Historical, Philological and Cultural Studies]. 2 (56): 146-158 (in Russian).

14. Maksimov S.M. 1929. Chuvashskaya muzyka. In: Pervyy vsechuvashskiy kraevedcheskiy s"ezd (15-21 iyunya 1928 goda v g. Cheboksarakh ChASSR). Tezisy dokladov i rezolyutsii [Chuvash music. The First All-Chuvash Local Lore Congress (June 15-21, 1928 in Cheboksary). Abstracts and resolutions]. Cheboksary, Izdanie obshchestva izucheniya Chuvashskogo kraya: 71-79 (in Russian).

15. Maksimov S.M. 1934. Vstupitel'naya stat'ya. In: 146 pesen, zapisannykh ot Gavrila Fedorova S. Maksimovym, F. Pavlovym, V. Vorob'evym i T. Paramonovym [Introductory article. 146 songs recorded by Gavril Fedorov S. Maximov, F. Pavlov, V. Vorobyov and T. Paramonov]. Cheboksary - Moscow, Chuvashgosizdat-Muzgiz: 3-16 (in Russian).

16. Medvedev V.V. 2009. Polevoy material avtora (Respublika Bashkortostan, Zilairskiy r-n, s. Berdyash) [Author's field material (Republic of Bashkortostan, Zilair district, v. Berdyash)] (in Russian).

17. Medvedev V.V. 2018. Polevoy material avtora (Respublika Bashkortostan, Karmaskalinskiy r-n, s. Suuk-Chishma) [Author's field material (Republic of Bashkortostan, Karmaskalinsky district, v. Suuk-Chishma)] (in Russian).

18. Medvedev V.V., Malakhova L.P. 2018. «Sovetizatsiya» traditsionnoy kul'tury chuvashey v 20-30-e gody XX veka. Nauchnyy dialog [ «Sovietization» of Traditional Chuvash Culture in the 20-30-s of the XX Century. Scientific Dialogue]. 3: 186-197 (in Russian).

19. Pavlov F.P. 1926. Chuvashi i ikh pesennoe i muzykal'noe tvorchestvo. Muzykal'noetnograficheskie ocherki [Chuvash and their song and music. Musical-ethnographic essays]. Cheboksary, Obshchestvo izucheniya mestnogo kraya, 65 (in Russian).

20. Panchenko A.A. Kul't Lenina i «sovetskiy fol'klor» [The cult of Lenin and «Soviet folklore»]. Available at: http://folk.spbu.ru/Reader/panch2.php?rubr=Reader-articles (accessed 10 January 2020) (in Russian).

21. Plaggenborg, S. 2000. Revolyutsiya i kul'tura: Kul'turnye orientiry v period mezhdu Oktyabr'skoy revolyutsiey i epokhoy stalinizma [Revolutionskultur: Menschenbilder und Kulturelle Praxis in Sowietrussland Zwischen Oktoberrevolution und Stalinsmus]. Saint-Petersburg, Neva, 414. (Plaggenborg S. 1996. Revolutionskultur: Menschenbilder und Kulturelle Praxis in Sowietrussland Zwischen Oktoberrevolution und Stalinsmus. Koln, Böhlau, 372).

22. Pogodina I.P. 2011. Pesennoe tvorchestvo pervykh chuvashskikh kompozitorov: ideologiya i iskusstvo [Songwriting of the first Chuvash composers: ideology and art]. Available at: https://pogodinkk.ucoz.ru/publ/pesennoe_tvorchestvo_pervykh_chuvashskikh_kompozitorov_ideologija_ i_iskusstvo_issledovanie/1-1-0-48 (accessed 10 January 2020) (in Russian).

23. Popova E.V. 2017. New (soviet) symbolism and the objective world of peasant everyday life. In: Etnokul'turnye protsessy v mnogonatsional'nom gosudarstve (k 100-letiyu revolyutsii 1917 goda v Rossii). Materialy Shestnadtsatykh Mezhdunarodnykh Sankt-Peterburgskikh etnograficheskikh chteniy. [Ethnocultural processes in a multinational state (on the 100th anni-versary of the 1917 revolution in Russia). Materials of the Sixteenth International St. Petersburg Ethnographic Readings]. Saint-Petersburg, The Russian Museum of Ethnography: 43-47 (in Russian).

24. Postanovlenie Politbyuro TsK RKP(b) «O politike partii v oblasti khudozhestvennoy literatury», 18 iyunya 1925 g. [Decision of the Politburo of the Central Committee of the RCP (B.) «On Party Policy in the Field of Fiction», June 18, 1925]. Available at: http://hist.msu.ru/ER/Etext/USSR/1925.htm (accessed 10 January 2020) (in Russian).

25. Postanovlenie Politbyuro TsK VKP(b) «O perestroyke literaturno-khudozhestvennykh organizatsiy», 23 aprelya 1932 g. [Resolution of the Politburo of the Central Committee of the All-Union Communist Party of Bolsheviks «On the restructuring of literary and artistic organizations», April 23, 1932]. Available at: http://www.refsru.com/referat-16420-16.html (accessed 10 January 2020) (in Russian).

26. Romanov N.R. 1960. Chuvashskie poslovitsy, pogovorki i zagadki [Chuvash proverbs, sayings and riddles]. Cheboksary, Chuvashskoe gosudarstvennoe izdatel'stvo, 359 (in Russian). 
27. Sirotkin M.Ya. 1965. Chuvashskiy fol'klor: ocherk ustno-poeticheskogo narodnogo tvorchestva [Chuvash folklore: an essay oral poetic folk art]. Cheboksary, Chuvashskoe knizhnoe izdatel'stvo, 132 (in Russian).

28. Halbwachs M. 2007. Sotsial'nye ramki pamyati [Les cadres sociaux de la mémoire]. Moscow, Novoe izdatel'stvo, 348. (Halbwachs M. 1994. Les cadres sociaux de la mémoire. Paris, Albin Michel, 374).

29. Chuvashi [Chuvashs]. Moscow, Nauka, 2017 (in Russian).

30. Chuvashi: etnograficheskoe issledovanie. Ch. 2. Dukhovnaya kul'tura / Pod redaktsiey M.Ya. Sirotkina, M.I. Ivanova [Chuvash: ethnographic study. Part 2. Spiritual culture / Edited by M.Ya. Sirotkina, M.I. Ivanova]. Cheboksary, Chuvashskoe knizhnoe izdatel'stvo, 1970. 308 (in Russian).

31. Shnirel'man V.A. 2016. Sotsial'naya pamyat' i obrazy proshlogo. Novoe proshloe [Social Memory and Images of the Past. The New Past]. 1: 100-123 (in Russian).

\section{Ссылка для цитирования статьи Link for article citation}

Медведев В.В., Попов М.В. 2020. Трансформация песенного фольклора чувашей в 20-30-е годы XX века: к вопросу о «советизации» традиционной культуры. Via in tempore. История. Политология, 47 (2): 350-358. DOI 10.18413/2687-0967-2020-47-2-350-358.

Medvedev V.V., Popov M.V. 2020. Transformation of song folklor of the chuvashi in the 20-30s of the XX century: to the question about the «sovietization» of traditional culture. Via in tempore. History and political science, 47 (2): 350-358 (in Russian). DOI 10.18413/2687-0967-2020-47-2-350-358. 